\title{
BMJ Open Childhood hospitalisation and related deaths in Hanoi, Vietnam: a tertiary hospital database analysis from 2007 to 2014
}

\author{
Nhung T T Nguyen, ${ }^{1,2,3}$ Tran Minh Dien, ${ }^{4}$ Christian Schindler, ${ }^{1,2}$ Nguyen T B Lien, ${ }^{4}$ \\ Nicole Probst-Hensch, ${ }^{1,2}$ Vu T H Lan, ${ }^{3}$ Nino Künzli, ${ }^{1,2}$ Laura Perez ${ }^{1,2}$
}

To cite: Nguyen NTT, Dien TM, Schindler C, et al. Childhood hospitalisation and related deaths in Hanoi, Vietnam: a tertiary hospital database analysis from 2007 to 2014. BMJ Open 2017;7:e015260. doi:10.1136/ bmjopen-2016-015260

- Prepublication history and additional material is available. To view please visit the journal (http://dx.doi.org/ 10.1136/ bmjopen-2016-015260).

Received 23 November 2016 Revised 25 April 2017 Accepted 1 June 2017

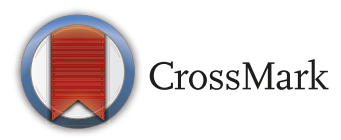

${ }^{1}$ Department of Epidemiology and Public Health, Swiss Tropical and Public Health Institute, Basel, Switzerland

${ }^{2}$ University of Basel, Basel, Switzerland

${ }^{3}$ Faculty of Fundamental Sciences, Hanoi University of Public Health, Hanoi, Vietnam ${ }^{4}$ Surgical Intensive Care Unit, Vietnam National Children's Hospital, Hanoi, Vietnam

Correspondence to Nhung T T Nguyen; nhung.nguyen@unibas.ch

\section{ABSTRACT}

Objective To describe hospital admission and emergency visit rates and potential risk factors of prolonged hospitalisation and death among children in Hanoi. Study design A retrospective study reviewed 212216 hospitalisation records of children (aged 0-17) who attended the Vietnam National Children's Hospital in Hanoi between 2007 and 2014. Four indicators were analysed and reported: (1) rate of emergency hospital visits, (2) rate of hospitalisation, (3) length of hospital stay and (4) number of deaths. The risk of prolonged hospitalisation was investigated using Cox proportion hazard, and the risk of death was investigated through logistic regressions. Results During 2007-2014, the average annual rate of emergency visits was 2.2 per 1000 children and the rate of hospital admissions was 13.8 per 1000 children. The annual rates for infants increased significantly by 3.9 per 1000 children during 2012-2014 for emergency visits and 25.1 per 1000 children during 2009-2014 for hospital admissions. Digestive diseases (32.0\%) and injuries (30.2\%) were common causes of emergency visits, whereas respiratory diseases (37.7\%) and bacterial and parasitic infections (19.8\%) accounted for most hospital admissions. Patients with mental and behavioural disorders remained in the hospital the longest (median $=12$ days). Morbidities related to the perinatal period dominated mortality causes $(32.5 \%$ of deaths among those admitted to the hospital. Among the respiratory diseases, pneumonia was the leading cause of both prolonged hospitalisation and death.

Conclusions Preventable health problems, such as common bacterial infections and respiratory diseases, were the primary causes of hospital admissions in Vietnam.

\section{INTRODUCTION}

Many families in low-income and middle-income countries rely on hospital visits to receive a broad range of healthcare. Hospital registries in these settings are an administrative tool and can provide objective information on the state of health of the population. ${ }^{1}$ Hospitalisation patterns can reveal opportunities for better care and
Strengths and limitations of this study

- The study capitalised on the availability of hospital records from the biggest tertiary hospital in Northern Vietnam, with 1300 beds

- The data compiled 8years (2007-2014) of information, revealing hospital admission and emergency visit trends for all diagnoses and potential predictors of prolonged stays and death in hospital.

- The study does not capture information about socioeconomic conditions, environmental factors and crowding.

- No distinction was made between new visits and readmission of the same patients.

- The data come from one tertiary hospital only.

prevention, identify emerging threats and assist in setting relevant public policies. ${ }^{2-4}$

In Vietnam, extensive information about childhood health patterns is readily available through national reports, such as the Country Report ${ }^{5}$ or the Annual Report Statistic, published by the Vietnam Ministry of Health. ${ }^{6}$ These reports show a declining trend in childhood mortality, from 58.0 per 1000 live births in 1990 to 23.2 per 1000 live births in 2012. ${ }^{5}$ However, the reports are limited to presenting rates of malnutrition, immunisation coverage and the absolute number of cases of and deaths due to some vaccine-preventable infectious diseases, like measles, tuberculosis, typhoid fever, diphtheria and neonatal tetanus. ${ }^{6}$ Evidence has shown that the leading causes of premature deaths among Vietnamese children are infectious diseases and drowning. ${ }^{6-8}$ Yet information on rates of disease or death due to other common paediatric pathologies, as well as quality-of-care indicators for these diseases, is still missing from national records. 
To address this gap, we collected data from the electronic registry of the Vietnam National Children's Hospital (VNCH) in Hanoi for all children under 18 years of age, who were residents of Hanoi $(27 \%$ of the total Hanoi population) and who were hospitalised and discharged between 2007 and 2014. With 1300 beds and 13 clinical departments, VNCH is the largest tertiary care centre for children in Northern Vietnam. Every day, approximately 2000-3000 children visit the hospital for a health check-up. Of these, 200 children are admitted to the hospital as inpatients. According to the 2016 annual report of the $\mathrm{VNCH},{ }^{9} 95 \%$ of Hanoi children visited the hospital directly via the VNCH's outpatient department. Only $5 \%$ of all patients were transferred from the provincial hospital (Saint Paul) or from other sector hospitals, such as Post Hospital. About 10\% of hospital admissions went through the emergency room; these included severe cases of respiratory, liver or heart failure. Scheduled outpatient visits accounted for about $0.05 \%$ of all admissions. $^{9}$

Our analysis aimed to understand the patterns and time trends of paediatric hospitalisations in Vietnam. We evaluated the rates of emergency visits, hospital admissions and deaths, as well as the length of hospital stay (LOS), among Hanoi children. We examined how these indicators vary by diagnoses, age, sex and residential location.

\section{METHODS}

\section{Hospital data source}

We obtained individual inpatient records from the VNCH electronic database, covering the period from 2007 to 2014. The hospital records included patient identification, gender, date of birth, home address, date of admission, discharge diagnoses (including codes according to the International Classification of Diseases, 10th Revision (ICD10), and disease name), date of discharge and health status at discharge. With the exception of the emergency department, all hospital departments collected data electronically from 2007. The emergency department commenced electronic data collection beginning in 2012. We included the records of children with residence in Hanoi only. Ethical approval was obtained from the ethical committee of the VNCH. Quality control and quality assurance processes were developed and implemented to ensure the validity of data (online supplementary file 1 ).

\section{Outcome indicators}

We analysed the database to obtain the following indicators: (1) rates of emergency visits and hospital admissions by age group and sex, (2) percentage of emergency visits, hospital admissions and deaths by diagnoses and age group, and (3) predictors of prolonged LOS and death. Age at admission year was classified into three groups: < 1 year, $1-4$ years and $5-17$ years.

Emergency visits were defined as admission to and discharge from the hospital on the same day. Emergency room data were only collected electronically from 2012; thus, we present data for the period 2012-2014. Average annual rates of emergency visits per 1000 children were computed by dividing the average annual number of emergency visits (in a 3-year period) by the size of the age-sex-specific population of Hanoi children in 2013.

Hospital admissions were defined as hospital stays for at least one night. Average annual rates of hospital admission per 1000 children were calculated as the average annual number of hospital admissions divided by the population of Hanoi children in 2010. Analyses were stratified by age and sex. We described disease frequencies for different discharge diagnoses according to ICD10's main chapters (online supplementary file 1 ). We additionally considered subgroups of respiratory diseases, including pneumonia (ICD10 J12-J18), bronchitis (ICD10 J20, J21), asthma (ICD10 J45), influenza (ICD10 J11), upper respiratory diseases (ICD10 J00-J06) and other respiratory diseases (ICD10 J07-J10, J19, J22-J44, J46-J99), as these diseases are the main causes of hospitalisation in most low-income and middle-income countries. To illustrate trends in the annual number of hospitalisations and emergency visits, we analysed these rates for children under age 5 from 2009 to 2014. Children under age 5 were chosen specifically because illnesses in this age group can affect the development of children later in life. We also derived annual hospitalisation rates of pneumonia, asthma, influenza, upper respiratory disease and gastroenteritis (ICD10 A08-A09) for children under 5.

The population size of Hanoi children was derived from one of two sources, depending on the year. Population data for 2009 were extracted from the 2009 population census, as reported by the General Statistics Office. ${ }^{10}$ Population data for all other years were obtained from the respective annual population reports published by the Hanoi Population and Family Planning Branch (HPFPB).$^{11}$ Information in the 2009 population census was published elsewhere. ${ }^{10}$ In this study, we only used age-specific and gender-specific information for the Hanoi population. The HPFPB derives data from quarterly updated censuses conducted by collaborators at the community level.

\section{Predictor analysis}

We used Cox proportion hazard regression to evaluate the risk of prolonged hospitalisation (or LOS) as a function of potential predictors including age, sex, residential location, year of admission and diagnosis. Stays of deceased children were not included in these analyses. Residential location was classified into three groups, namely inner city, outer city and unidentified location (online supplementary file 1). We defined LOS as the number of nights a child stayed in the hospital, calculated as the date of discharge minus the date of admission. Since LOS in the hospital was not normally distributed, both mean and median of LOS were reported. Hazard ratios (HRs) $>1$ mean that patients in the respective group were, on average, discharged earlier (shorter hospital stay) than 
those in the reference group. Since HRs varied over time for most of the predictor variables, we presented HRs for those discharged the day after a one-night stay and following a five-night stay in the hospital $\left(\mathrm{HR}_{1}\right.$ and $\left.\mathrm{HR}_{5}\right)$.

Similarly, to assess the contribution of predictors of death during hospitalisation, we performed logistic regressions with a predefined set of predictor variables consisting of age group, sex, residence location and year of admission. Separate models were computed for children who made emergency visits and for children who were admitted to the hospital. Two additional logistic regression models were developed, including indicator variables for respiratory diseases, to evaluate the risk of death from respiratory diseases. To define 'death', we combined two adverse outcomes, namely death at the hospital and 'worse' as a heath status at discharge. Culturally, Vietnamese people wish their family members to experience their last moments of life at home. Therefore, children in terminal states, with little chance of survival, were sent home at the family's request to die at home. In such cases, health status at discharge was usually coded as 'worse'. Results were considered statistically significant if two-sided $\mathrm{p}$ values were below 0.05 . All analyses were conducted using Stata V.13.1.

\section{RESULTS}

\section{Emergency room visits}

Between 2012 and 2014, there were 12389 paediatric emergency visits to the $\mathrm{VNCH}$ originating from Hanoi. This corresponds to an average annual rate of 2.2 visits per 1000 children (table 1). Emergency visit rates were higher among boys than among girls (2.6 vs 1.7 visits per 1000 children, respectively). The average rate of emergency visits was highest among infants, with 5.6 visits per
1000 infants, followed by children aged 1-4 years, with approximately 5.5 visits per 1000 children (table 1 ).

Across all ages, diseases of the digestive system accounted for the largest proportion $(32.0 \%)$ of all emergency visits. Injuries ranked second (30.2\%). Respiratory diseases $(11.4 \%)$ and bacterial infections $(7.8 \%)$ were also important causes of emergency visits (figure 1). This ranking differed across age groups. For infants, digestive diseases $(39.6 \%)$ were followed by respiratory infections $(17.1 \%)$ as the leading causes of emergency visits, whereas for children aged $1-4$, digestive diseases (34.3\%) and injuries $(32.9 \%)$ were the leading causes, followed by respiratory diseases $(10.3 \%)$. Injuries were the prime reason for emergency visits $(41.3 \%)$ among children aged 5-17 years (figure 1). Online supplementary file 1 provides percentages of emergency visits for each group.

Of the respiratory diseases, upper respiratory illness was the primary cause $(46.0 \%)$ for emergency visits. Among infants, pneumonia was the leading respiratory cause for emergency visits (41.1\%) (online supplementary file 1).

\section{Hospital admissions}

VNCH data show that 199827 children from Hanoi were hospitalised between 2007 and 2014. This translates into an average annual hospitalisation rate of 13.8 per 1000 children. Hospitalisations were also higher among boys than among girls (16.9 per 1000 boys compared with 10.4 per 1000 girls). The hospital admission rate was more than three times higher for infants than for children aged $1-4$ years (85.7 per 1000 vs 23.4 per 1000 children, respectively) (table 1).

Respiratory diseases were the most frequent, accounting for $37.7 \%$ of all hospital admissions. Bacterial and parasitic infections were the second most common disease group $(19.8 \%)$, followed by digestive disorders (10.2\%)

Table 1 Number, percentage and annual rate of emergency visits and hospital admissions of Hanoi children referred to the National Children Hospital in Vietnam, by gender and age group

\begin{tabular}{|c|c|c|c|c|c|c|}
\hline \multirow[b]{2}{*}{ Variable } & \multicolumn{2}{|c|}{ Emergency visits (2012-2014) } & \multicolumn{4}{|c|}{ Hospital admissions (2007-2014) } \\
\hline & $\mathbf{N}$ & $\%$ & Rate per $1000^{*}$ & $\mathbf{N}$ & $\%$ & Rate per $1000 \dagger$ \\
\hline All & 12389 & 100 & 2.22 & 199827 & 100 & 13.82 \\
\hline \multicolumn{7}{|l|}{ Gender } \\
\hline Female & 4481 & 36.2 & 1.72 & 70631 & 35.4 & 10.38 \\
\hline Male & 7908 & 63.8 & 2.65 & 129196 & 64.7 & 16.88 \\
\hline \multicolumn{7}{|l|}{ Age group } \\
\hline$<1$ & 2387 & 19.3 & 5.55 & 81648 & 40.9 & 85.74 \\
\hline $1-4$ & 7765 & 62.7 & 5.47 & 88061 & 44.1 & 23.42 \\
\hline $5-9$ & 1883 & 15.2 & 1.13 & 23470 & 11.8 & 6.28 \\
\hline $10-14$ & 339 & 2.7 & 0.26 & 6184 & 3.1 & 1.69 \\
\hline $15-17$ & 15 & 0.1 & 0.02 & 464 & 0.2 & 0.20 \\
\hline
\end{tabular}

*Annual mean rate of emergency visits (per 1000 children)=1000xannual mean number of cases (2012-2014)/number of children in the respective gender or age group, using the midyear 2013 Hanoi children population as denominator.

†Annual mean rate of hospital admissions (per 1000 children)=1000xannual mean number of hospital admissions (2007-2014)/number of the respective gender or age using the midyear 2010 Hanoi children population as denominator. 
a)Percent distribution of the five most frequent disease groups of all emergency visits

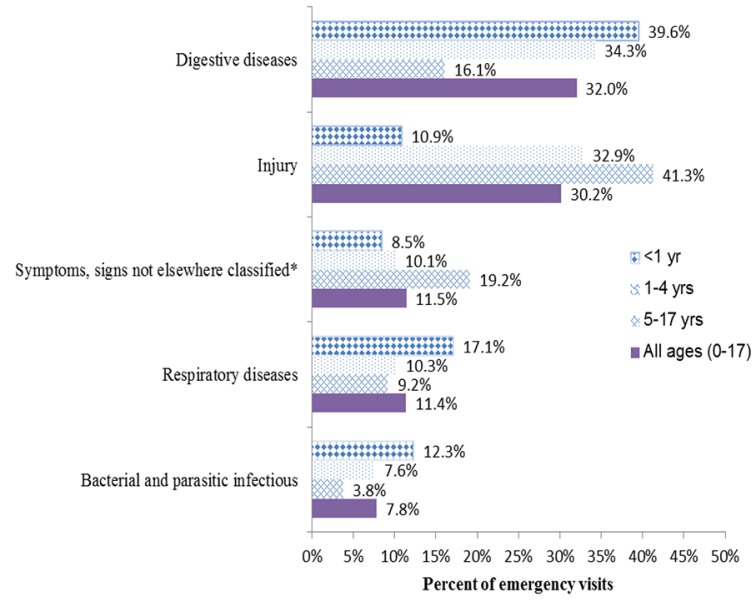

b)Percent distribution of the five most frequent disease groups of all hospital admissions

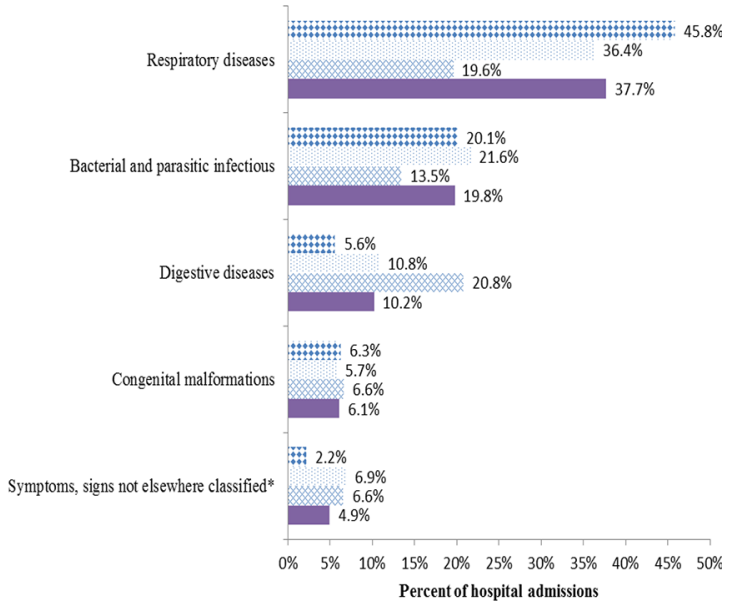

Figure 1 Distribution of the five most frequent diagnoses among (A) emergency visits (2012-2014) and (B) hospital admissions (2007-2014) in Hanoi children, stratified by age group. *Symptoms, signs not elsewhere classified are defined as discharge diagnoses from the International Classification of Diseases, 10th Revision code from R10-R19, which included abdominal or pelvic pain, nausea and vomiting.

(figure 1). This trend was consistent across age groups, except in the case of infants where diseases related to the perinatal period (birth trauma, haemorrhagic disorder of fetus and newborn, and so on) ranked as the third leading cause of hospital admissions (9.0\%) (online supplementary file 1$)$.

Of the respiratory disease-related admissions, pneumonia accounted for $54.1 \%$ and bronchitis for $19.1 \%$. Among infants, pneumonia accounted for $66.8 \%$ of all respiratory disease-related admissions. Pneumonia and upper respiratory diseases were the leading causes of hospital admissions among children aged 1-4 years (45.5\% and $27.9 \%$, respectively) (online supplementary file 1).

\section{Predictors of hospitalisation and LOS}

Across all types of stays, the average length of hospitalisation was 5.2 nights. Except for infants, the average length of hospitalisation increased with age, from 4.3 nights for children aged 1-4 years to 6.9 nights for adolescents (table 2). Boys were more likely to have shorter stays than girls. Children living in the outer regions of the city had a significantly higher likelihood of longer stays than children residing in the inner city $\left(\mathrm{HR}_{1}=0.86,95 \%\right.$ CI 0.85 to 0.87 ). In general, having been hospitalised due to a non-communicable disease increased the LOS, compared with having been hospitalised due to a communicable disease. For instance, the average LOS of patients with mental and behaviour-related diseases was 12.2 nights, compared with 3.8 nights for those with bacterial and parasitic infections (data not shown). Table 2 shows the top 5 disease groups with the longest hospital stays; all five are non-communicable diseases, with mental health disorders at the top. Among the respiratory infections, pneumonia accounted for the longest average LOS (6.4 nights), followed by bronchitis (4.9 nights). Those admitted due to upper respiratory disease had, on average, the shortest length of stay (2.9 nights).

Table 2 also depicts the probabilities of discharge from the hospital on day 2, after having stayed one night $\left(\mathrm{HR}_{1}\right)$, and on day 6 , after having stayed five nights $\left(\mathrm{HR}_{5}\right)$. In particular, the probability of discharge was higher for upper respiratory diseases than for pneumonia, but this difference decreased from day 2 to day 6 , with the HRs on day 2 and day 6 being 2.06 (95\% CI 1.95 to 2.19) and 1.46 (95\% CI 1.40 to 1.53 ), respectively.

\section{Predictors of mortality during hospitalisation}

In the period 2012-2014, 131 deaths occurred among children visiting the hospital for emergency situations, that is, $1.1 \%$ of all children making emergency visits did not survive the day of the visit (table 3 ). Those deaths occurred more frequently among infants (108 out of the 131 cases). Diseases relating to the perinatal period were the primary cause of death $(38.9 \%$ of all emergency visit deaths). Death related to cardiovascular diseases and congenital malformations each contributed to $11.5 \%$ of the total. While perinatal-period diseases and congenital malformations were the leading causes of death among infants, cardiovascular diseases and injuries were the main causes of deaths among children aged $1-4$ years (table 3 ).

Among the hospitalised children, 3142 deaths were registered during 2007-2014, corresponding to $1.6 \%$ of all paediatric hospital admissions. Infants deaths contributed 2502 cases to the total $(79.6 \%)$. As in emergency visits, diseases relating to the perinatal period were the leading cause of death during hospitalisation (32.5\%). Respiratory diseases accounted for $18.3 \%$ of deaths during hospitalisation. As shown in table 3, disease related to the perinatal period was the dominant factor leading to death among infants $(40.8 \%)$, whereas bacterial and parasitic 
Table 2 Hospital duration (mean, median, minimum, maximum) (days) by age group, gender, residential location and disease group and HR of discharge on day 2, after having stayed for one night $\left(\mathrm{HR}_{1}\right)$, and on day 6 , after having stayed for five nights $\left(\mathrm{HR}_{5}\right)$, respectively, among children in Hanoi, Vietnam

\begin{tabular}{|c|c|c|c|c|c|}
\hline \multirow[b]{2}{*}{ Categories } & \multirow[b]{2}{*}{ Mean } & \multirow[b]{2}{*}{ Median } & \multirow[b]{2}{*}{ Maximum } & \multicolumn{2}{|l|}{ HR (95\% Cl)† } \\
\hline & & & & After one night $\left(\mathrm{HR}_{1}\right)$ & After five nights $\left(\mathbf{H R}_{5}\right)$ \\
\hline All & 5.20 & 4 & 80 & & \\
\hline \multicolumn{6}{|l|}{ Age group } \\
\hline$<1$ & 6.41 & 5 & 66 & Ref & Ref \\
\hline $1-4$ & 4.31 & 3 & 80 & $1.51(1.49 \text { to } 1.52)^{*}$ & $1.41(1.39 \text { to } 1.42)^{\star}$ \\
\hline $5-9$ & 4.37 & 3 & 77 & $1.52(1.49 \text { to } 1.55)^{\star}$ & $1.40(1.38 \text { to } 1.42)^{\star}$ \\
\hline $10-14$ & 5.48 & 3 & 80 & $1.28(1.24 \text { to } 1.32)^{\star}$ & $1.22(1.19 \text { to } 1.25)^{\star}$ \\
\hline $15-17$ & 6.87 & 4 & 58 & 1.04 (0.93 to 1.17$)$ & $1.01(0.93$ to 1.10$)$ \\
\hline
\end{tabular}

Gender

\begin{tabular}{|c|c|c|c|c|c|}
\hline Female & 5.32 & 4 & 80 & Ref & Ref \\
\hline Male & 5.13 & 4 & 80 & $1.05(1.04 \text { to } 1.06)^{\star}$ & $1.04(1.03 \text { to } 1.05)^{*}$ \\
\hline \multicolumn{6}{|l|}{ Residential location } \\
\hline Inner city & 4.76 & 3 & 77 & Ref & Ref \\
\hline Outer city & 5.97 & 4 & 80 & $0.86(0.85 \text { to } 0.87)^{\star}$ & $0.88(0.87 \text { to } 0.89)^{\star}$ \\
\hline Unidentified location & 5.58 & 4 & 66 & $0.94(0.91 \text { to } 0.98)^{\star \star}$ & $0.91(0.88 \text { to } 0.94)^{\star \star}$ \\
\hline \multicolumn{6}{|c|}{ Top 5 disease groups with the longest hospital duration $\ddagger$} \\
\hline Mental and behavioural disorders & 12.18 & 12 & 41 & Ref & Ref \\
\hline $\begin{array}{l}\text { Factors influencing health status and } \\
\text { contact with health services }\end{array}$ & 10.51 & 5 & 76 & $2.78(1.87 \text { to } 4.12)^{\star}$ & $2.00(1.41 \text { to } 2.84)^{\star}$ \\
\hline Causes related to perinatal period & 10.29 & 7 & 61 & $2.79(2.40 \text { to } 3.24)^{\star}$ & $2.18(1.94 \text { to } 2.45)^{\star}$ \\
\hline Neoplasms & 9.57 & 6 & 80 & $2.61(2.24 \text { to } 3.03)^{*}$ & $1.99(1.77 \text { to } 2.23)^{*}$ \\
\hline $\begin{array}{l}\text { Endocrinal and nutritional and } \\
\text { metabolic diseases }\end{array}$ & 9.66 & 7 & 52 & $2.63(2.26 \text { to } 3.06)^{\star}$ & $2.15(1.92 \text { to } 2.42)^{\star}$ \\
\hline \multicolumn{6}{|l|}{ Respiratory diseases§ } \\
\hline Pneumonia & 6.42 & 6 & 30 & Ref & Ref \\
\hline Bronchitis & 4.91 & 4 & 30 & $1.63(1.58 \text { to } 1.68)^{\star}$ & $1.47(1.44 \text { to } 1.49)^{\star}$ \\
\hline Asthma & 4.28 & 4 & 27 & $1.76(1.67 \text { to } 1.86)^{\star}$ & $1.44(1.39 \text { to } 1.49)^{\star}$ \\
\hline Other respiratory diseases & 4.34 & 3 & 30 & $3.67(3.57 \text { to } 3.78)^{\star}$ & $2.05(2.02 \text { to } 2.09)^{*}$ \\
\hline Influenza & 3.02 & 2 & 30 & $3.27(3.08 \text { to } 3.46)^{\star}$ & $1.99(1.90 \text { to } 2.09)^{*}$ \\
\hline Upper respiratory disease & 2.92 & 2 & 30 & $2.06(1.95 \text { to } 2.19)^{*}$ & $1.46(1.40 \text { to } 1.53)^{*}$ \\
\hline
\end{tabular}

${ }^{*} \mathrm{p}<0.001,{ }^{* *} \mathrm{p}<0.05$.

†HR $>1$ means higher probability of earlier discharge from hospital (thus, a shorter length of stay) than in the reference group. Hospital admissions are defined as staying at the hospital for at least one night.

¥HR was estimated from Cox proportional hazard regression model with length of hospitalisation as outcome, and age group, sex, residential location, year of admission and disease groups as predictors.

$\S$ The model has adjusted for respiratory diseases instead of disease groups. Stays of deceased children were not included in these analyses. Ref, reference group.

infections were the leading cause of death among children aged $1-4$ years (representing $26.3 \%$ of deaths in this age group) (table 3 ).

Table 4 illustrates the association of demographic factors with death in hospital during emergency visits and hospitalisation. Boys were significantly less likely to die in the hospital than girls $\left(\mathrm{OR}_{\text {emergency visit }}=0.69,95 \% \mathrm{CI} 0.48\right.$ to $0.98 ; \mathrm{OR}_{\text {hospital admission }}=0.83,95 \% \mathrm{CI} 0.77$ to 0.90$)$. Children living in the outer regions of the city were substantially more likely to die than those living in the inner city
$(\mathrm{OR}$ isit: $3.12,95 \%$ CI 2.13 to 4.56 ; $\mathrm{OR}_{\mathrm{l}}$ $2.34,95 \%$ CI 2.18 to 2.52 ).

Table 4 also compares the risk of death from respiratory diseases, adjusted for demographic factors. Children admitted with pneumonia were more likely to die than those hospitalised due to asthma or bronchitis.

\section{Trends in children under 5}

Overall, the rates of emergency visits and hospital admissions for children under 5 increased over the study period 


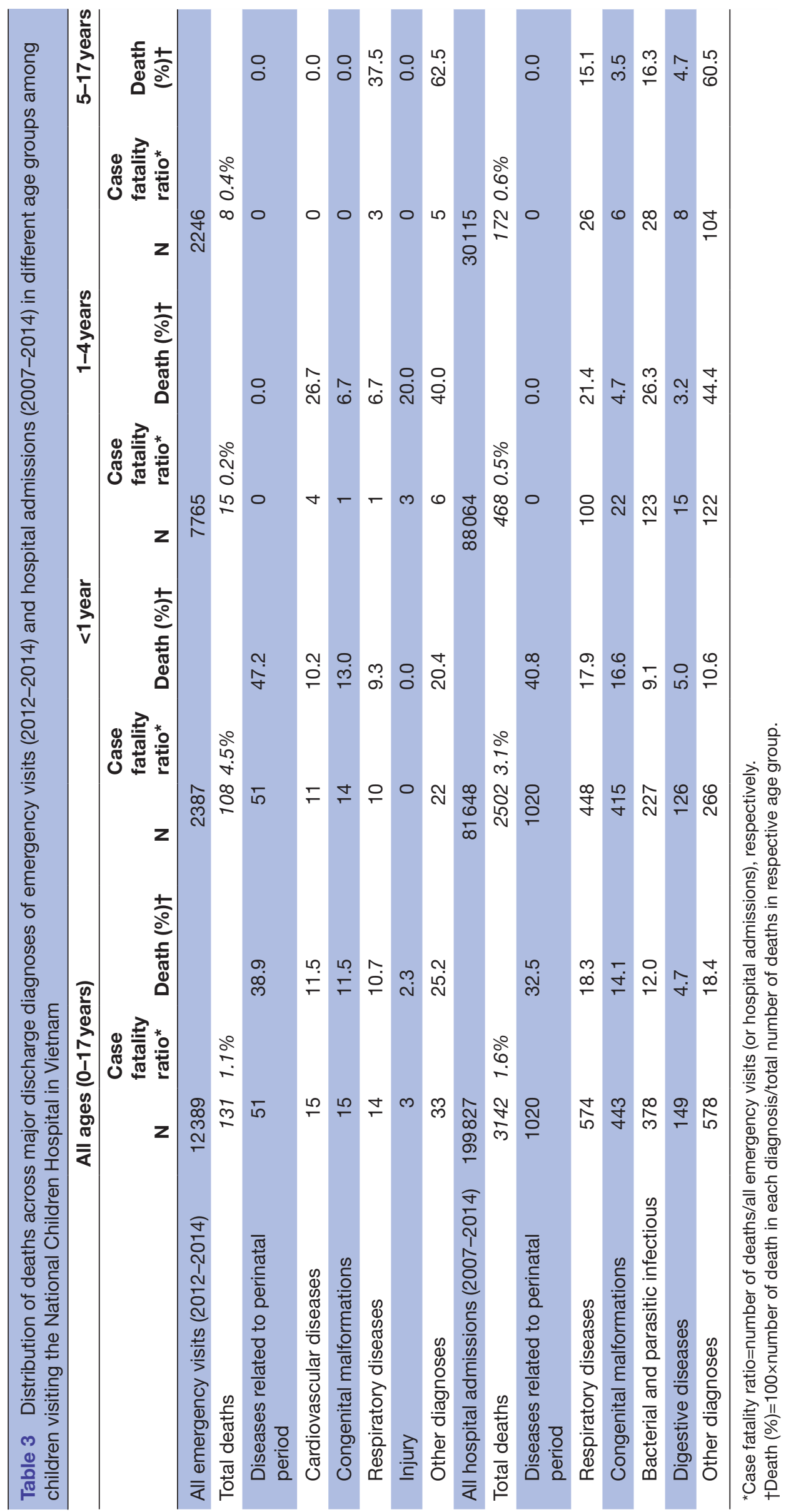

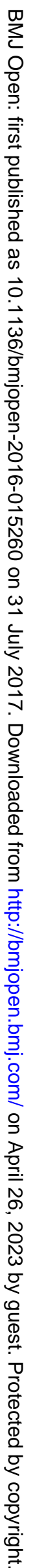


Table 4 Logistic regression of deaths with demographic and diagnosis factors for emergency visits (2012-2014) and hospital admissions (2007-2014) among children in Hanoi, Vietnam

\begin{tabular}{|c|c|c|c|c|c|c|}
\hline \multirow[b]{2}{*}{ Predictors } & \multicolumn{3}{|c|}{ Emergency visit (2012-2014) } & \multicolumn{3}{|c|}{ Hospital admission (2007-2014) } \\
\hline & $\begin{array}{l}\text { Number of } \\
\text { deaths }\end{array}$ & $\begin{array}{l}\text { Death } \\
(\%)\end{array}$ & ORt (95\% Cl) & $\begin{array}{l}\text { Number of } \\
\text { deaths }\end{array}$ & $\begin{array}{c}\text { Death } \\
(\%)\end{array}$ & ORt (95\% Cl) \\
\hline Total & 131 & & & 3142 & & \\
\hline \multicolumn{7}{|l|}{ Age group } \\
\hline$<1$ & 108 & 4.5 & Ref & 2502 & 3.1 & Ref \\
\hline $1-4$ & 15 & 0.2 & $0.05(0.03 \text { to } 0.09)^{\star}$ & 468 & 0.5 & $0.19(0.17 \text { to } 0.21)^{\star}$ \\
\hline $5-9$ & 3 & 0.2 & $0.05(0.01 \text { to } 0.15)^{*}$ & 100 & 0.4 & $0.15(0.12 \text { to } 0.18)^{\star}$ \\
\hline $10-14$ & 4 & 1.2 & $0.34(0.12 \text { to } 0.94)^{\star \star}$ & 64 & 1.0 & $0.34(0.27 \text { to } 0.44)^{*}$ \\
\hline $15-17$ & 1 & 6.7 & $1.87(0.24$ to 14.84$)$ & 8 & 1.7 & 0.56 (0.28 to 1.13$)$ \\
\hline \multicolumn{7}{|l|}{ Gender } \\
\hline Female & 60 & 1.3 & Ref & 1211 & 1.7 & Ref \\
\hline Male & 71 & 0.9 & $0.69(0.48 \text { to } 0.98)^{\star *}$ & 1931 & 1.5 & $0.83(0.77 \text { to } 0.90)^{\star}$ \\
\hline \multicolumn{7}{|l|}{ Residence location } \\
\hline Inner city & 45 & 0.5 & Ref & 1197 & 1.0 & Ref \\
\hline Outer city & 79 & 2.6 & $3.12(2.13 \text { to } 4.56)^{*}$ & 1875 & 2.6 & $2.34(2.18 \text { to } 2.52)^{\star}$ \\
\hline Not identified location & 9 & 2.0 & $2.73(1.19 \text { to } 6.23)^{\star *}$ & 70 & 2.2 & $2.14(1.67 \text { to } 2.73)^{\star}$ \\
\hline \multicolumn{7}{|l|}{ Respiratory diseasesł } \\
\hline Pneumonia & 8 & 2.3 & Ref & 493 & 1.2 & Ref \\
\hline Bronchitis & 0 & 0.0 & NA & 9 & 0.1 & $0.05(0.03 \text { to } 0.10)^{*}$ \\
\hline Asthma & 1 & 1.3 & $0.78(0.05$ to 13.19$)$ & 4 & 0.2 & $0.26(0.10 \text { to } 0.72)^{\star \star}$ \\
\hline Upper respiratory diseases & 0 & 0.0 & NA & 0 & 0.0 & NA \\
\hline Influenza & 0 & 0.0 & NA & 3 & 0.2 & 0.33 (0.11 to 1.05$)$ \\
\hline Other respiratory diseases§ & 5 & 26.3 & $13.38(3.24 \text { to } 55.21)^{*}$ & 65 & 3.4 & $6.26(4.59 \text { to } 8.53)^{*}$ \\
\hline
\end{tabular}

Death $(\%)=100 \times$ number of death in the category/total number of case of emergency visits (or hospital admissions) in respective category of predictor variables.

Emergency visit defined as hospital admission and discharge on same day. Hospital admission defined as hospital stay of at least one night. ${ }^{*} \mathrm{p}<0.001,{ }^{* *} \mathrm{p}<0.05$.

†Logistic regression model was built with death as outcome, and age group, gender, residence location and year of admission for emergency visits as predictors.

$\ddagger$ Additional predictors in models.

§All five deaths during emergency visits and 51/65 deaths among hospital admissions in this group were due to respiratory failure (International Classification of Diseases, 10th Revision code J96).

NA, not applicable; Ref, reference group.

(online supplementary file 1). The rate of emergency visits among children under 5 went from 3.3 per 1000 in 2012 up to 7.3 per 1000 in 2014. Notably, the age-specific rate of emergency visits among infants increased by 3.9 per 1000 children (from 4.3 per 1000 to 8.2 per 1000) during 2012-2014.

Hospital admission rates among children under 5 increased slightly between 2009 and 2014 (from 32.8 to 39.9 per 1000 children). However, among infants, the rate of hospital admissions increased substantially, from 69.7 per 1000 in 2009 to 97.2 in 2013, with a slightly lower rate in 2014 (94.8 per 1000 children) (online supplementary file 1).

\section{DISCUSSION}

This study shows that Hanoi children visited the hospital for services that could be covered by primary care services. Hospital admissions reached an average rate of 13.8 per 1000 children/year, with stays lasting 5.2 days on average. These numbers are much higher than the statistics published for American children, with annual hospital admission rates for children aged 0-17 years of 7.9 per 1000 in 2012 and a mean LOS of 3.9 days. ${ }^{12}$ Our study shows that digestive diseases and respiratory diseases were the leading causes of hospitalisation.

Intestinal obstruction was the leading cause of emergency visits due to digestive diseases, accounting for $80.9 \%$ of those emergencies. VNCH is the national referral hospital and receives, as a result, the most complex cases, including intestinal obstruction. Therefore, these results are in line with expected patterns. If not treated 
A)

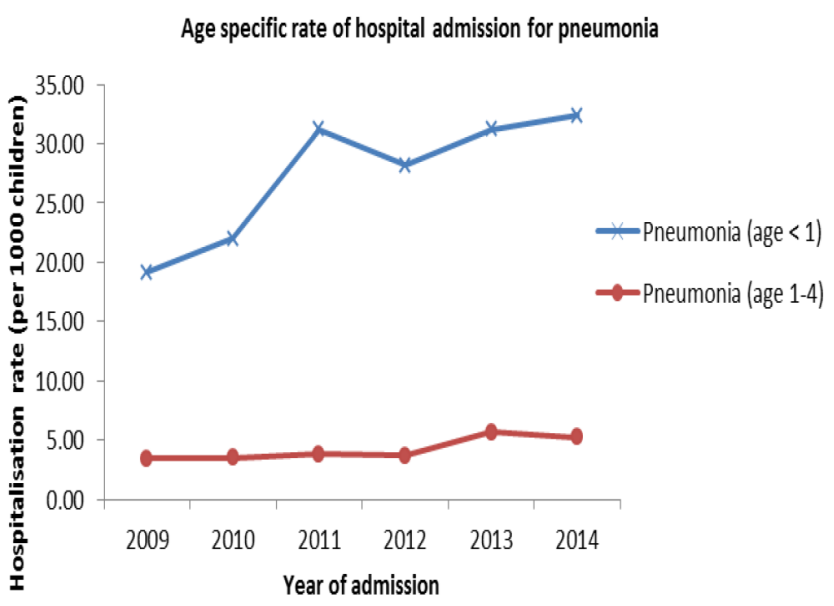

C)

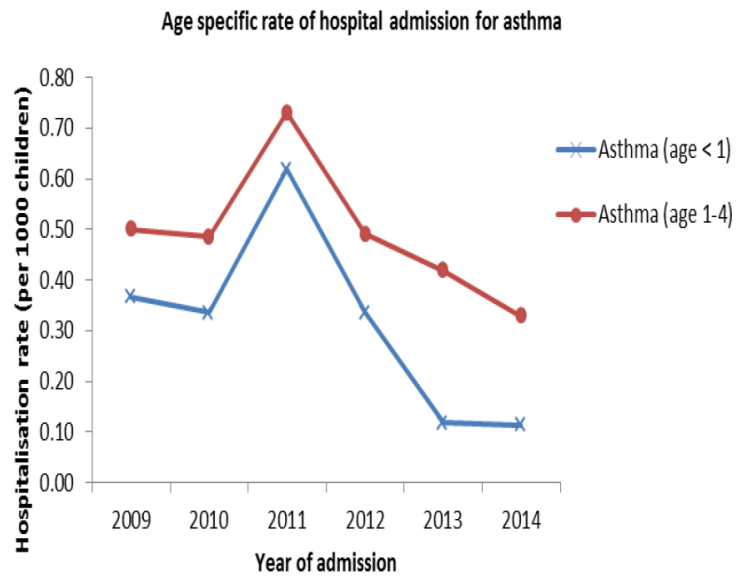

E)

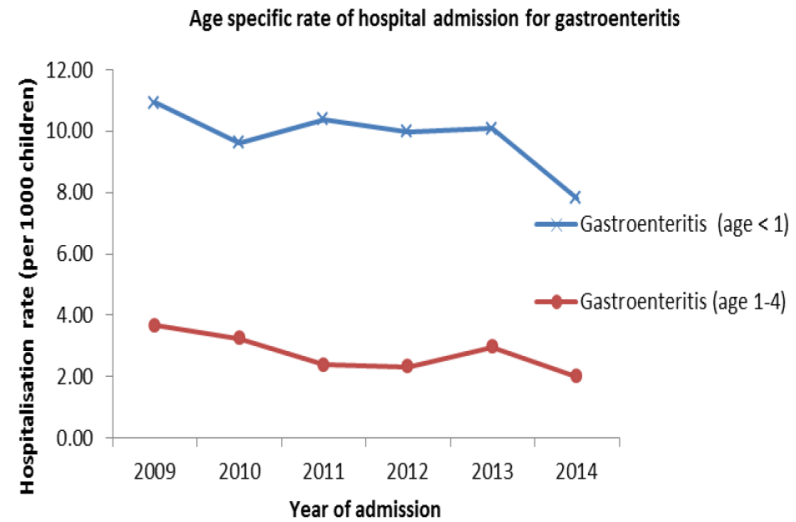

B)

Age specific rate of hospital admission for influenza

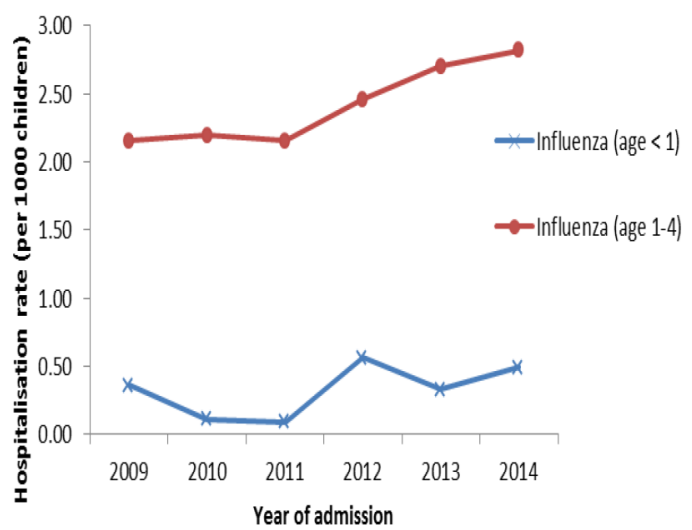

D)

Age specific rate of hospital admission for upper respiratory disease

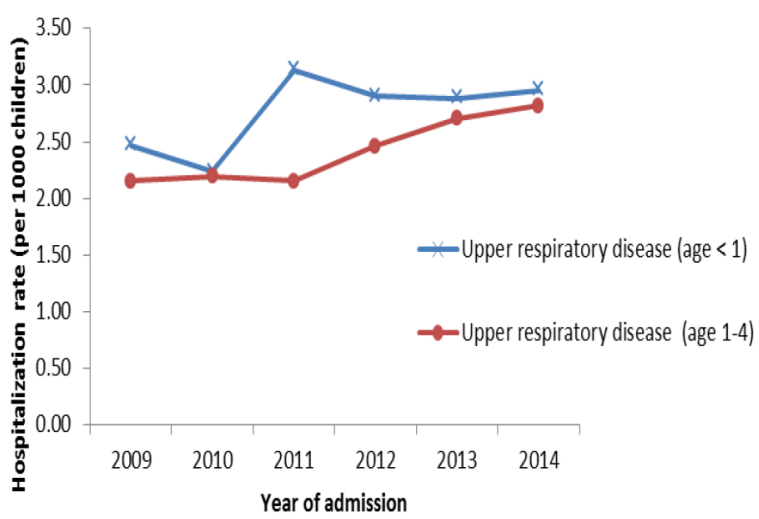

Figure 2 Illustrates the time trend of annual hospital admission rates for five specific diseases, namely (A) pneumonia, (B) influenza, (C) asthma, (D) upper respiratory disease and (E) gastroenteritis, for infants and children aged 1-4 years, from 2009 to 2014. Trends were similar for infants and children aged 1-4, in which hospitalisation rates tended to decrease for asthma and gastroenteritis. Admissions due to asthma peaked in 2011 but declined thereafter in both age groups. However, an increasing trend was observed for pneumonia, influenza and upper respiratory diseases. For instance, infant admission rates due to pneumonia increased from 19.2 per 1000 in 2009 to 32.4 per 1000 in 2014. 
early, intestinal obstruction is a severe and potentially lethal condition for children. ${ }^{13}$ Therefore, research on the causes and prevention of this disease is warranted in Vietnam.

We found that injuries were the second leading cause of emergency room visits, accounting for $30 \%$ of all emergency visits. According to the Vietnam National Injury report, the main causes of injury in children under 14 years of age were burns with fire or hot water. ${ }^{14}$ The low rate of injury-related hospital admissions is explained by the fact that severe injuries were transferred to other specialised hospitals, such as the National Burn Institute for burn cases or Viet Duc Hospital for other injury types. Our results add to the evidence showing that injury affects the health of Vietnamese children and highlight the need to strengthen injury prevention activities. ${ }^{14}$

Respiratory diseases are still the most important causes of hospital admissions for children, with pneumonia causing $24.5 \%$ of all emergency visits and $54.1 \%$ of total hospital admissions for respiratory diseases. As reported in other countries, ${ }^{15} 16$ pneumonia was a primary cause of prolonged hospitalisation and a major reason for death due to respiratory diseases. These findings are also consistent with the results from the Vietnam Burden of Disease and Injury in 2008, in which pneumonia was the leading cause of illness and premature death in children, especially those under the age of $5 .{ }^{7}$ We reported all data according to the ICD coding scheme used by VNCH; therefore, some data should be interpreted with caution. In the case of asthma, for example, reactive airway disease may be a better diagnostic description among the youngest children; asthma may be used inconsistently by physicians.

A further concern related to pneumonia is the upward trend shown in figure 2, predominantly among infants. There is a need to identify the causes of this severe disease and the reasons behind the increase to implement preventive strategies. Pneumonia in children has many possible causes, including individual characteristics, nutrition, vaccination, environmental tobacco smoking and air pollution. ${ }^{17} 18$ In Vietnam, the prevalence of smoking has declined among both women and men over the last decades. ${ }^{19}$ Similarly, as a result of implementing several nutrition and vaccination programmes, the rate of malnutrition has declined and the rate of vaccination has increased. ${ }^{5}$ Therefore, we hypothesise that atmospheric pollution may play a role in the risk of hospitalisation for pneumonia, as seen in Hong Kong, ${ }^{20}$ given the high concentrations reported for Hanoi. ${ }^{21}{ }^{22}$ Further investigations are required to determine a possible relationship.

The findings in this study show that the rates of emergency visits and of hospital admissions were higher for boys than for girls, although death rates were lower for the former. These findings are consistent with results from other studies ${ }^{23}$ For example, Axelson $e t a l^{23}$ reported that the infant mortality rate ratio of men:women in 2006 in Vietnam was 14.0:20.8, whereas the men:women ratio of the prevalence of diarrhoea in the 2 weeks preceding the interview was 7.5:6.1. Gender preferences among parents may explain these findings. In Vietnamese culture, boys are the privileged gender. ${ }^{24}$ As a consequence, parents may pay more attention to and act earlier on health problems for boys than for girls.

Our descriptive study has several limitations. First, while this is the first study to provide an overview of hospital admissions and emergency visits among children in Hanoi, the cross-sectional data do not allow us to examine possible causes of the observed patterns or the role of potentially relevant factors, such as socioeconomic conditions, environmental factors, crowding or infectious disease epidemics. Second, the study is based on registry data - that is, the number of visits or admissions - with limited additional information and no distinction between new visits and readmissions of the same patients. Therefore, we cannot derive information about patterns among diseased patients where readmissions may be relevant. Indeed, the rate of hospital admissions or emergency visits might be higher among patients with non-infectious diseases than among those with infectious diseases. Third, data come from one hospital in Hanoi; hence, the results do not represent all children of Hanoi. Nonetheless, the VNCH has 1300 beds compared with 50 beds in the second national hospital (Paediatric Department, Bach Mai Hospital). Thus, the former hospital represents an important fraction of all hospitalisations. Fourth, given that children above 13 years of age could be transferred to adult health facilities, rather than to the VNCH, particularly for injuries or heart disease, the total hospitalisation rate among adolescents in the Hanoi region may be underestimated.

Our analysis raises several questions for future investigations. First, what are the reasons behind the upward trends in hospitalisations due to largely preventable diseases, such as respiratory disease? This issue could be addressed by using hospital data combined with data about environmental factors, like air quality and weather. Second, what is the relevance of the household's social class, hospital capacity, residential distance to hospitals or changes in insurance policies with regard to admission patterns and the LOS at the hospital? Third, the LOS in the hospital showed no particular trend over time (data not shown), yet improvements in treatment and technology may result in shorter stays. This raises the question of how best to increase the efficiency of the hospital system and possibly reduce costs without jeopardising quality of care. Understanding those factors will provide the information needed to plan and implement evidence-based strategies of prevention and treatment.

\section{CONCLUSION}

Utilisation of the hospital was common among children in Hanoi, particularly among children under 5 years of age. Respiratory and digestive diseases were the prime causes of both emergency visits and hospital admissions. Study results show that pneumonia was the most common 
respiratory disease, causing both prolonged hospitalisation and death. As seen in other parts of the world, ${ }^{3}$ many of these respiratory and digestive diseases could be prevented. The data collected in this study show that further research is needed to characterise the aetiologies of respiratory diseases and digestive diseases in Hanoi. This will provide the basis for targeted public health interventions to reduce these burdens.

Acknowledgements We thank the staff from the Administration Department in the VNCH for contributing time for data cleaning work. The Vietnam General Statistic Office provides data on population census in 2009, and the Hanoi Population and Family Planing Branch provides data on population from 2010 to 2014. Ms Le Thi Thu Hien (Public Health Freelance Professional) edited the English language for the initial draft, and Amena Briët (Swiss TPH) edited the English language for the final version.

Contributors NTTN and LP conceived the study. NTTN drafted the initial manuscript. NTTN, TMD, NK, NPH and LP developed the study design. NTBL integrated and extracted data from electronic system. NTTN undertook the data analyses. CS provided expertise in the data management and data analysis. All authors contributed to the interpretation of the results. Each of the author contributed to the preparation and editing of the manuscript. All authors have seen and approved the submission of this version of the manuscript and take full responsibility for the manuscript.

Competing interests None declared.

Patient consent Detail has been removed from this case description/these case descriptions to ensure anonymity. The editors and reviewers have seen the detailed information available and are satisfied that the information backs up the case the authors are making.

Ethics approval The National Hospital of Pediatrics Ethics Committee.

Provenance and peer review Not commissioned; externally peer reviewed.

Data sharing statement Individual record of hospital admissions and emergency visits collected for this study were given approval limited to use for this study only. However, the authors would be happy to make the data available upon request. Individuals may contact nhung.nguyen@unibas.ch.

Open Access This is an Open Access article distributed in accordance with the Creative Commons Attribution Non Commercial (CC BY-NC 4.0) license, which permits others to distribute, remix, adapt, build upon this work non-commercially, and license their derivative works on different terms, provided the original work is properly cited and the use is non-commercial. See: http://creativecommons.org/ licenses/by-nc/4.0/

(C) Article author(s) (or their employer(s) unless otherwise stated in the text of the article) 2017. All rights reserved. No commercial use is permitted unless otherwise expressly granted.

\section{REFERENCES}

1. Schoenman JA, Sutton JP, Elixhauser A, et al. Understanding and enhancing the value of hospital discharge data. Med Care Res Rev 2007;64:449-68.
2. MacFaul R, Werneke $U$. Recent trends in hospital use by children in England. Arch Dis Child 2001;85:203-7.

3. Gill PJ, Goldacre MJ, Mant D, et al. Increase in emergency admissions to hospital for children aged under 15 in England, 1999-2010: national database analysis. Arch Dis Child 2013;98:328-34.

4. Hasegawa K, Tsugawa Y, Brown DF, et al. Childhood asthma hospitalizations in the United States, 2000-2009. J Pediatr 2013;163:1127-33.

5. Vietnam Ministry of Health. Success Factors for Women's and Children's Health, Vietnam. 20 Avenue Appia, 1211 Geneva 27, Switzerland: World Health Organization, 2015.

6. Vietnam Ministry of Health. Health Statistics Yearbook- 2013 Hanoi. Vietnam: Ministry of Health, 138 Giang Vo, Ba Dinh, Hanoi, 2015.

7. Nhung NTT, Long TK, Linh BN, et al. Estimation of Vietnam National Burden of Disease. Asia Pac J Public Health 2013;2008.

8. Vietnam Ministry of Health. joined Annual Health Report 2015. Hanoi, Vietnam: Vietnam Ministry of Health 2016.

9. Vietnam National Children's Hospital. Annual report. Hanoi, Vietnam: Vietnam National Children's Hospital, 2016.

10. Central Population and Housing Census Steering Committee. The 2009 Vietnam Population andHousing Census - Major Findings. Vietnam General Statistics Office, 6B Hoang Dieu, Ba Dinh, Hanoi, 2010. https://unstats.un.org/unsd/demographic/sources/census/ wphc/Viet\%20Nam/Vietnam-Findings.pdf.

11. Hanoi Population and Family Planning Branch. Annual Report of Population. Ly Thai To, Hoan Kiem, Hanoi, Vietnam: Hanoi Population and Family Planning Branch, 2010-20142014.

12. Witt WP, Weiss AJ. A E. Overview of Hospital Stays for Children in the United States 2012. December 2014 ed. Rockville, MD, USA: Agency for Healthcare Research and Quality, 2014.

13. Janik JS, Ein SH, Filler RM, et al. An assessment of the surgical treatment of adhesive small bowel obstruction in infants and children. J Pediatr Surg 1981;16:225-9.

14. Ministry of Labor and Invalid Affairs. Vietnam National Injury Survey 2010: general Report. Hanoi, Vietnam, 2013.

15. Black RE, Morris SS, Bryce J. Where and why are 10 million children dying every year? Lancet 2003;361:2226-34.

16. Panickar JR, Dodd SR, Smyth RL, et al. Trends in deaths from respiratory illness in children in England and Wales from 1968 to 2000. Thorax 2005;60:1035-8.

17. Walker CLF, Rudan I, Liu L, et al. Global burden of childhood pneumonia and diarrhoea. The Lancet 2013;381:1405-16.

18. Zar HJ, Madhi SA, Aston SJ, et al. Pneumonia in low and middle income countries: progress and challenges. Thorax 2013;68:1052-6.

19. Bui TV, Blizzard L, Luong KN, et al. Declining prevalence of tobacco smoking in Vietnam. Nicotine Tob Res 2015;17:831-8.

20. Qiu H, Tian LW, Pun VC, et al. Coarse particulate matter associated with increased risk of emergency hospital admissions for pneumonia in Hong Kong. Thorax 2014;69:1027-33.

21. Hai CD, Kim Oanh NT, Oanh NTK, local E. Effects of local, regional meteorology and emission sources on mass and compositions of particulate matter in Hanoi. Atmos Environ 2013;78:105-12.

22. Vietnam Ministry of Natural Resources and Environment. National state of Environment 2010: vietnam Urban Air Environment. Hanoi: Vietnam Ministry of Natural Resources and Environment, Vietnam, 2012.

23. Axelson H, Gerdtham UG, Ekman B, et al. Inequalities in reproductive, maternal, newborn and child health in Vietnam: a retrospective study of survey data for 1997-2006. BMC Health Serv Res 2012;12:456.

24. Bélanger D. Son preference in a rural village in North Vietnam. Stud Fam Plann 2002;33:321-34. 